\title{
Movimentos sociais de sexualidade e gênero: análise do acesso às políticas públicas
}

\author{
Guilherme Gomes Ferreira \\ Pontifícia Universidade Católica do Rio Grande do Sul (PUCRS)
}

\author{
Beatriz Gershenson Aguinsky \\ Pontifícia Universidade Católica do Rio Grande do Sul (PUCRS)
}

Movimentos sociais de sexualidade e gênero: análise do acesso às políticas públicas

Resumo: Este artigo busca problematizar as formas com que os movimentos sociais de diversidade sexual e de gênero têm acessado as políticas públicas no Brasil. Para isso, analisa as especificidades e necessidades de reconhecimento de determinados grupos sociais historicamente vulneráveis que disputam a própria concepção de identidade. Nesta direção, são tematizadas as contradições presentes nesta disputa uma vez que os movimentos tanto avançam no reconhecimento identitário quanto reforçam estigmas e vulnerabilidades. Sob a perspectiva do método dialético-crítico, o artigo parte de situações concretas para uma análise mais ampla e teórico-reflexiva da realidade. Palavras-chave: Movimentos Sociais. Sexualidade. Gênero. Políticas públicas.

\section{Social Movements of Sexuality and Gender: analysis of access to public policies}

Abstract: This article analyzes the ways that social movements in support of sexual and gender diversity have accessed public policies in Brazil. It looks at the specificities and needs for recognition of specific social groups that have been historically vulnerable, and which dispute the very concept of identity. It analyzes the contradictions in this dispute given that the movements both advance in identity recognition and also reinforce stigmas and vulnerabilities. From a dialectical and critical perspective, the article uses concrete situations to conduct a broader theoretical and reflexive analysis of reality.

Keywords: Social movements. Sexuality. Gender. Public policies. 


\section{Introdução}

Entender a sexualidade e o gênero não como categorias fixas, mas em constante movimento e não classificáveis permite construir uma ideia de como esses temas vêm sendo tratados no cenário social contemporâneo como algo fronteiriço, quer dizer, que contorna as fronteiras morais (MISKOLCI, 2007) daquilo que as sociedades consideram como algo natural e normal.

Não é da atualidade que os temas da sexualidade e do gênero são invisibilizados pelos campos políticos, sociais e também acadêmicos (BENTO, 2006), mesmo tendo ganhado centralidade em diferentes áreas do saber com o surgimento do movimento feminista e $\mathrm{LGBT}^{1}$ - no Brasil, mais profundamente na década de 1980 (GREEN, 2000; LOURO, 1997). Contraditoriamente, diferentes instituições ideológicas ${ }^{2}$, tais como a família, a religião, a medicina, o sistema escolar, de justiça, de segurança, entre outras, constroem significados sobre a sexualidade e o gênero (FOUCAULT, 1988) ditando modelos de normalidade e de comportamento, produzindo saberes de controle sobre corpos e desejos.

Trabalhar com esses temas se conforma, portanto, como um desafio aos movimentos que atuam com as políticas de grupos sociais vulneráveis, pois embora lutem por afirmar seus direitos em um cenário de desigualdade social, são constantemente sucateados e colocados literalmente na fronteira. Isso ocorre, sobretudo, quando o tema em disputa diz respeito à sexualidade e ao gênero, como afirmam Nobre e Werle (2009) ao se referirem aos movimentos LGBTs e de defesa do aborto que têm suas reivindicações de reconhecimentos consideradas como excessivas e até mesmo obsoletas.

Preconiza-se nesse trabalho a mediação entre aspectos estruturais e históricos no que diz respeito à sexualidade e ao gênero como conceitos amplos, e aspectos concretos que envolvem o surgimento de políticas públicas, legislação e instituições voltadas para os segmentos sociais que discutem sexualidade e gênero.

\section{Sexualidade e gênero em perspectiva}

Se, por um lado, existem na história das sociedades, determinados comportamentos sexuais mais ou menos pactuados como normais, de outro lado, esses comportamentos têm sido empregados pelos sujeitos através de um ou outro formato, consensualizados segundo uma ou outra visão de ser humano e de mundo. O que outrora era permitido ou negado ganha novas configurações, influenciando diretamente os arranjos legais, morais e sociais.

\subsection{Sexo e gênero como dispositivos históricos}

Para discorrer sobre uma linha histórica acerca das normas sobre a sexualidade e o gênero na sociedade brasileira, é imprescindível entender como as ideias sobre esses temas foram sendo construídas nas diferentes sociedades, através da história e no plano da cultura, começando pelo advento da Igreja Católica Apostólica Romana e, integrante a isso, do Cristianismo, há mais de dois mil anos (MAGISTÉRIO DA IGREJA, 2000).

Antes do advento do Cristianismo e da Igreja Católica Apostólica Romana, o homoerotismo e as relações sexuais entre pessoas do mesmo sexo eram comuns como instrumento de educação sexual entre homens mais velhos que ensinavam aos mais jovens o conhecimento dos seus corpos e das práticas sexuais (ULLMANN, 2007). Contudo, com o surgimento das religiões, em especial a católica e evangélica, as práticas sexuais começaram a ter por objetivo a procriação, descartando, dessa feita, relações eróticas e sexuais que tivessem como base o prazer. Para Trevisan (2004, p. 19), essa ideia não ampara apenas um ideal religioso, mas também moral e capitalista, pois:

Além de ser inútil para a reprodução da espécie, a prática homossexual solaparia a família (em cujo seio se geram os novos consumidores) e seus padrões ideológicos (cuja ordem é consumir). [...] o vácuo políticoideológico, a crise do capitalismo e a recrudescência dos credos religiosos institucionalizados criaram terreno fértil para as execrações morais, insufladas agora por um milenarismo de olho no capital.

A moral cristã também vai ao encontro da ideologia da família burguesa do século 19, na qual o burguês é reconhecido como o bom cristão por ser monogâmico, se reproduzir e acumular o capital por meio do matrimônio, legitimando as posses materiais hereditárias através da propriedade privada. O casamento também começou a ser valorizado porque interessava à manutenção das classes sociais, já que os sujeitos unidos em matrimônio eram considerados uma única célula de controle. Tais ideias são amparadas por Lafargue (1932, p. 5) ao dizer também que "o cristianismo é, por excelência, a religião das sociedades que descansam sobre as bases da propriedade individual e da exploração do trabalho assalariado; isso, tem sido, é e será diga-se e faça-se o que se quiser - a religião da burguesia". 
No final do século 19 e início do século 20, o homossexual emerge na figura de uma personagem e sua conduta passa a ser medida em relação à sua sexualidade (FOUCAULT, 1988). As práticas eróticas e sexuais, que até então eram consideradas um pecado pelo olhar religioso, ganham as características de anormalidade, desvio e doença. Até 1973, a homossexualidade figura na Classificação Internacional de Doenças (CID).

Já no Brasil, entre os anos 1964 e 1986, diferentes posições sobre a homossexualidade pululavam nos discursos políticos: o movimento de esquerda política, de modo geral, acreditava que a luta por direitos específicos contra o sexismo, racismo e homofobia dividiria suas forças, argumentando pela união do povo contra a ditadura. Enquanto isso, os estudantes homossexuais reclamavam que a esquerda brasileira era homofóbica (GREEN, 2000).

Não bastando ser considerada doença e pecado, a sexualidade diferente da heterossexual também recebe a característica de crime, como mostram os dados do relatório da Internacional Lesbian, Gay, Bissexual, Trans and Intersex Associacion (ILGA), ao afirmar que a homossexualidade é, no mundo, considerada delito e resulta em pena de morte em cinco países e aprisionamento em 84 países/entidades federativas. O mesmo relatório aponta que na América Latina e no Caribe, onze ${ }^{3}$ são os países que punem com pena de prisão e/ou castigos corporais a homossexualidade e, por outro lado, apenas cinco países - incluindo o Brasil - e duas entidades reconhecem a união entre pessoas do mesmo sexo, seja pelo casamento igualitário, seja através de substitutivo legal (ILGA, 2012).

É possível entender, assim, que a normativa da heterossexualidade enquanto instrumento de reprodução das ideias dominantes se mantém como o principal matiz do atual comportamento sexual e afetivo do qual se permite expressão. Mais do que uma normativa da orientação sexual - o desejo sexual e afetivo que uma pessoa é capaz de dirigir a sexo e gênero -, a heteronormatividade 4 é um arcabouço de diretrizes que dizem respeito também a determinado vestuário, gosto musical, jeito de andar, à determinada afinidade por acessórios e por operações no corpo, personalidade e identidade. Isso porque entender a quem o sujeito destina seu afeto e desejo sexual - que conceitua determinadas práticas sexuais e relacionamentos afetivos - é apenas uma nuance da sexualidade. É preciso entender que as identidades sexuais e de gênero também dizem respeito a como o sujeito se expressará cultural e socialmente.

Com relação ao gênero, seu debate é marcado pelo movimento feminista no intuito de negar o essencialismo com o qual o tema era tratado quando se falava a respeito de ser mulher e de ser homem como constituições naturais e determinadas unicamente pela biologia (SCOTT, 1995). Esse marco nos estudos de gênero, ocorrido entre os anos 1960 e $1970^{5}$, trouxe à tela o debate sociológico sobre ser mulher e sobre ser homem, mesmo que no início desses estudos ainda se pensasse nesses gêneros como categorias distintas e contrárias, como binômios.

Sobre esse binarismo do gênero, ou seja, a ideia de que as pessoas são contempladas por uma representação masculina ou feminina de gênero, de perto é uma lógica perversa que procura normatizar e normalizar os corpos. Butler (2010), nesse aspecto, ensina que o gênero é tomado de performatividade na medida em que "é resultante de um regime que regula as diferenças de gênero. Neste regime, os gêneros se dividem e se hierarquizam de forma coercitiva" (BUTLER, 2010, p. 64).

O gênero é compulsoriamente inscrito no corpo assim que esse nasce e, antes mesmo de nascer, no conjunto de expectativas e pressuposições de comportamentos, gostos e subjetividades. É quando o corpo é maculado pela cultura (BENTO, 2006). De modo que, na aparentemente simples expressão "é uma menina", não se está só inscrevendo o gênero, mas fabricando o corpo feminino no campo social. Nesse sentido, é importante pensar que não há como separar a parte do corpo dita natural daquela que foi sendo construída culturalmente e denominada de gênero, pois nem a cultura, nem a biologia fazem parte de um estado determinado onde o primeiro recai sobre o segundo. Ao contrário, pode-se pensar o gênero como "uma sofisticada tecnologia social heteronormativa, operacionalizada pelas instituições médicas, linguísticas, domésticas, escolares e que produzem constantemente corpos-homens e corpos-mulheres" (BENTO, 2006, p. 87). Segundo a autora, os corpos, então, assumirão sua aparência de gênero na medida em que se reiteram continuamente no cotidiano os atos que conferem masculinidade ou feminilidade, sendo isso chamado de gênero performático (BENTO, 2006). E assim, portanto, que corpo e gênero estarão sempre em relação, e justamente por isso não podem ser concebidos como duas polaridades contrárias ou dissociadas.

\subsection{Teoria Queer e Teoria Identitária em relação à sexualidade e o gênero}

Se a heterossexualidade sempre existiu, também foi assim com todas as outras possibilidades de sexualidade. Todavia, a categoria homossexualidade é uma invenção do século 19, como aponta Louro (2001) ao dizer que a prática homossexual, mesmo sendo ainda considerada desviante, já passava a ser também reconhecida como tipo especial e distintivo de sexualidade do ser humano, o que perdurou até meados da década de 1970. Pouco a pouco, segundo a autora, começa a surgir a ideia de uma comunidade homossexual, na qual seus 
integrantes se encontrariam representados em razão de suas orientações sexuais, buscando direitos de igualdade mesmo se considerando diferentes do restante da sociedade heterossexual. Apoiavam-se, assim, em uma identidade homossexual que deveria, sobretudo, ser pública.

Durante muito tempo e ainda na atualidade, diferentes autores dos estudos sobre a sexualidade e o gênero têm pensado essas categorias como identidades fixas, alinhadas e compartilhadas universalmente, mesmo que aceitem, como Mott (2003), recortes transversais de raça/etnia, idade, classe social, entre outros. Para entender como isso funciona, é necessário recorrer aos estudos sobre identidade e ancorar a compreensão em autores que dirão que a identidade, ao contrário do que se possa pensar, não é estática nem permanente, mas acompanha a dinamicidade e o movimento da história e do real (FERNANDES, 2006).

No entanto, esses autores, conhecidos por construírem políticas identitárias no seio da discussão sobre sexualidade e gênero, compreendem tais temas sob uma perspectiva essencialista (COLLING, 2010), unificada (LOURO, 2001) e conservando representações sociais vigentes (MISKOLCI, 2009). Enquanto trabalham pela inclusão dos não heterossexuais na dinâmica social, lutando por reconhecimento e legitimação, acabam por esquecerem de fazer a crítica à esses modelos já definidos, sob o discurso de que essas identidades devem ser aceitas a qualquer custo ${ }^{6}$. Essa luta, que é também "um apelo no social para que a identidade dos sujeitos permaneça igual a um determinado tipo de identidade, que é produzida pela cultura do seu tempo histórico" (FERNANDES, 2006, p. 2), demanda que homossexuais, bissexuais, travestis e transexuais consolidem suas identidades de um modo transcultural e transecular, de modo que coincida com a identidade idealizada ainda na década de 1970 quando do surgimento dos guetos e comunidades homossexuais.

Um contraponto importante a essa discussão é o que se convencionou chamar na história de Teoria Queer $^{7}$, como método analítico que além de defender a desnaturalização da sexualidade e do gênero - como fenômenos não implícitos da natureza, mas de ordem também política, social e cultural - percebe as identidades e a própria sexualidade de forma muito mais fluída, apontando as fraturas e contradições da estrutura social, contestando os "regimes normalizadores que criam tanto as identidades quanto sua posição subordinada no social” (MISKOLCI, 2009).

É nesse sentido que o conceito de identidade não pode representar algo estanque, tampouco deve ser percebido como caráter de idêntico em uma sociedade onde a diversidade é tamanha (FERNANDES, 2006), pois se o pensamento for esse, estaria corroborando com a ideia falsa, por exemplo, de uma identidade sexual naturalmente heterossexual, construída em um determinado tempo histórico e estabelecida no campo da cultura.

Essas contradições nas políticas identitárias podem ser percebidas também quando se trata do movimento de mulheres, ou, como se convencionou chamar na contemporaneidade, sobre as políticas de gênero mesmo que, majoritariamente, essas políticas não sejam para os homens.

Butler (2010) em suas análises sobre as questões relativas ao gênero aponta que o movimento feminista pressupunha em sua origem e na essência, uma identidade definida e genericamente compartilhada para a categoria de mulheres, na qual elas se reconheceriam e se representariam. Para a autora, no entanto, não há um sujeito do feminismo e quiçá as mulheres ocupam esse lugar simplesmente por serem biologicamente mulheres:

[...] já não está claro que a teoria feminista tenha que tentar resolver as questões da identidade primária para dar continuidade à tarefa política. Em vez disso, devemos nos perguntar: que possibilidades políticas são consequências de uma crítica radical das categorias de identidade? Que formas novas de política surgem quando a noção de identidade como base comum já não restringe o discurso sobre políticas feministas? E até que ponto o esforço para localizar uma identidade comum como fundamento para uma política feminista impede uma investigação radical sobre as construções e as normas políticas da própria identidade? (BUTLER, 2010, p. 9-10).

Lutar pela igualdade entre mulheres e homens - como se todos fossem idênticos, sem levar em consideração a diversidade - ou lutar pela equidade em razão das diferenças entre mulheres e homens - o que, por vezes, marca antigas relações de gênero e naturaliza a subordinação da fêmea ao macho como algo essencial de seus sexos - quaisquer dessas posições endossam e definem as pessoas, incumbido papeis de gênero, modos e condições de vida, distintos para homens e mulheres, porque colocam mais uma vez as relações humanas no binarismo compulsório do qual todos fazem parte.

\subsection{Sexualidade em relação com o sistema econômico}

Mas a produção de identidades também está atrelada às condições objetivas e subjetivas para o seu reconhecimento. Silveira (2002, p. 104) entende que os processos subjetivos possuem relação com a interioridade dos sujeitos, "tensionados e interpelados através das expressões concretas da sociabilidade hegemônica". 
Nesse sentido, as condições objetivas, materiais, econômicas e jurídicas se entrelaçam com as condições subjetivas, culturais e ideológicas para a produção e reprodução de identidades reconhecidas no seio de uma determinada ordem social.

A identidade de gênero feminina para uma mulher, embora a sociedade tenha se transformado e muitos dos conceitos moralistas, machistas e sexistas tenham perdido força, ainda está atrelada à ideia do bom comportamento, do recato, do cuidado, da sensibilidade. Tudo que foge a isso é visto como moralmente incorreto. $\mathrm{Na}$ ordem capitalista vigente, esses ideais morais quando alinhados ao regime econômico tendem a mais uma vez normalizar corpos e modos de vida, criticando determinados usos e operações no corpo e na imagem, e muito mais objetivamente quando se trata do corpo feminino já que esse é duplamente disciplinado por uma economia patriarcal e capitalista.

No que se refere à sexualidade, ao uso do sexo/gênero e do corpo como instrumento de prazer, no sistema capitalista e patriarcal, serão considerados realizáveis apenas para o desejo masculino, heterossexual e monogamicamente. Discriminar-se-á, com isso, toda expressão da sexualidade e do sexo que fuja e que conteste esses moldes, transformando a sexualidade "em espaço de exercício de relações de dominação, com o recurso à violência para subordinação do oprimido(a). Violência sempre presente, mesmo que apenas nas piadas, cantadas e ameaças" (GODINHO, 1989, p. 5).

Os fenômenos da sexualidade e do gênero, quando afirmados socialmente no campo dos direitos humanos, surgem alinhados a uma luta que buscava novas relações de igualdade e liberdade (GOHN, 1997). Percebe-se, entretanto, que, na história dessas lutas, os movimentos se apoiaram muito mais em políticas de identidade em detrimento de questionarem a própria ordem social vigente. O que, se, por um lado, prioriza a afirmação de seus espaços na sociedade, por outro lado acarreta maior vulnerabilidade ao não transformar a raiz cultural de moralidade e da desigualdade.

\section{Considerações sobre os movimentos sociais de sexualidade e gênero no Brasil}

Na quadra histórica contemporânea, a permanência dos movimentos sociais combativos na dinâmica social tem se mostrado cada vez mais complicada. No seu resgate sobre o surgimento dos movimentos sociais e das organizações não governamentais (ONGs) no Brasil, Gohn (1997) afirma que houve uma alteração substancial nas relações entre o Estado e o chamado Terceiro Setor da sociedade, sobretudo entre os anos 1990. Nessa década, ainda quando o governo era considerado inimigo, figura uma nova postura dos movimentos sociais de um modo geral no qual eles passam a ser copartícipes das políticas públicas. Seus agentes foram sendo gradativamente capturados pelo Estado na forma de parceiros, e com o surgimento de movimentos sociais ainda mais interessados em aliarem-se ao poder estatal, os mais combativos foram se fragilizando no que pesa as suas participações políticas.

Essa é uma realidade que até hoje se mantém e é potencializada nos movimentos sociais de gênero e sexualidade pelo fato de trabalharem com temas considerados fronteiriços, ou seja, que recebem pouca visibilidade e atenção do Estado. Isso em uma época histórica onde cada vez mais fortemente a religião e a bancada política evangélica têm disputado territórios com os movimentos que defendem, entre outras bandeiras, a livre orientação sexual, o empoderamento feminino, a autodeterminação sobre o corpo e a descriminalização do aborto etc.

\subsection{Acesso às políticas públicas como estratégia de afirmação da identidade e da diferença}

Como bem afirma Wagner (2004), os movimentos sociais tematizam questões que parecem, em um primeiro momento, não possuir soluções satisfatórias de acordo com a ideologia de cunho neoliberal que a sociedade capitalista assume em sua organização. Já para Souza (1991, p. 99), os movimentos sociais são "formas de enfrentamento das contradições sociais que se expressam em reações coletivas a algo que se apresenta como bloqueio ou afronta aos interesses e às necessidades coletivas de determinado grupo social". E, especialmente, para alguns movimentos, como é o caso dos que trabalham com as questões de gênero e diversidade sexual, a atenção volta-se para as particularidades de grupos discriminados em oposição a um foco universal.

Tanto Souza (1991) quanto Wagner (2004) compreendem a década de 1970 como o auge do aparecimento dos movimentos sociais brasileiros, tanto no que diz respeito às formulações teóricas como ao surgimento culminante de movimentos sociais, ideia essa amparada por Green (2000), Costa, Machado e Prado (2008), Jesus (2010) e Taques (2007) ao dizerem que as marcas, protestos e fundação dos movimentos sociais de diversidade sexual e de gênero surgem com força na década de 1970, mais especificamente entre os anos 1978 e 1979, com o nascimento do primeiro grupo homossexual no Brasil. 
Pela primeira vez, lésbicas falavam abertamente sobre a discriminação que encontravam. Estudantes gays reclamavam que a esquerda brasileira era homofóbica. Defensores de Fidel Castro e da revolução cubana argumentavam que a luta por direitos específicos, contra o sexismo, racismo e a homofobia, iria dividir a esquerda. Eles argumentavam que o povo devia se unir na luta geral contra a ditadura. A primeira controvérsia dentro do movimento homossexual brasileiro começava a se delinear. Os discursos já tinham sido apresentados. Dentro de um ano, questões táticas sobre alinhamento com outros movimentos sociais ou manutenção da autonomia política e organizacional iria rachar o Somos, então o maior grupo de direitos homossexuais no país, deixando outras organizações espalhadas pelo país desanimadas e sem direção (GREEN, 2000, p. 274).

Tais manifestações eram nada mais que a explosão de sujeitos coletivos até então invisíveis que se uniam em torno da defesa de seus direitos, batalhando por visibilidade. Numa época em que eclodia a busca por cidadania, como a retirada da homossexualidade em 1973 da Classificação Internacional de Doenças, também se destinava a população de gays, bissexuais e transgêneros a figurar como responsável pela disseminação do dito câncer e peste gay ou da responsabilização divina, cujo auge foi no ano 1983 e cujo estigma social é reforçado e reafirmado até os dias atuais. Nessa época histórica, "lutas sociais contra a desigualdade de gênero, consolidação de movimentos identitários, irrupção de novos arranjos, impactos do HIV/aids na forma de experimentar a sexualidade, conformam o cenário da necessidade de afirmação dos movimentos sexuais" (FROEMMING, 2007, p. 13).

Voltando à atualidade e adentrando o campo das políticas públicas, o contexto de sobrevivência dos movimentos sociais de gênero e sexualidade pode ser ainda mais perverso do que o foi na história, pois se por um lado tais movimentos têm construído nos últimos anos importantes políticas e ações de afirmação de suas identidades e necessidades como o direito de união estável aos homossexuais em todo o território brasileiro, a Lei Maria da Penha, a inclusão do trabalho sexual na Classificação Brasileira de Ocupações e o direito à cirurgia de transgenitalização para transexuais pelo Sistema Único de Saúde, só para citar preliminarmente alguns - por outro lado é comum que uma parcela dessa visibilidade seja conquistada ora pelo viés vitimizador de suas identidades, ora pelo viés criminalizador de identidades alheias às suas. Como acontece com o movimento LGBT em garantir financiamento com projetos de prevenção à Aids, ao mesmo tempo em que pretende desvincular essa população do estigma da doença, por exemplo.

Tomando primeiramente como exemplo esse caso, é interessante pensar no paradoxo que afirma e ao mesmo tempo nega a relação entre a epidemia do HIV/aids e os homossexuais. É inegável o impacto da epidemia para a produção da visibilidade da condição homossexual, que ganha, com o seu advento, uma imensa perversidade. É certo que

na história dessas lutas, os movimentos se apoiaram muito mais em políticas de identidade em detrimento de questionarem a própria ordem social vigente. O que, se por um lado prioriza a afirmação de seus espaços na sociedade, por outro lado acarreta maior vulnerabilidade ao não transformar a raiz cultural de moralidade e da desigualdade. nenhum outro grupo social possui a intimidade que a população LGBT possui com a epidemia do HIV e isso porque o estigma a que estava sendo subjugada a população gay masculina era imenso já que, segundo Green (2000), era direta a associação entre o HIV e os homossexuais com maior poder e recursos econômicos para viajar aos Estados Unidos e a Europa (onde houve os primeiros casos de transmissão), pois a própria condição homossexual também era rapidamente relacionada à promiscuidade.

A identificação do HIV/aids como tema correlacionado ao movimento social de diversidade sexual e de gênero perdura até a contemporaneidade e não é por acaso, portanto, que esses movimentos se mantêm também sob o financiamento de projetos sociais de prevenção do HIV/aids. Isso, todavia, é uma das contradições desses movimentos, pois se utilizam de estratégias de autovitimização para poderem sobreviver no jogo social. Se por um lado os homossexuais e bissexuais masculinos caracterizam de fato um grupo social vulnerável à epidemia, por outro lado a utilização de financiamentos na área da saúde a favor da prevenção ao HIV/ aids deixa de lado, por vezes, questões de cidadania e de acesso à rede de serviços que também requisitam respostas da política de saúde, pintando mais uma vez as contradições e os trânsitos entre invisibilidade e visibilidade perversa reproduzidos de dentro e de fora desses movimentos. 
Essas relações também se materializam no movimento LGBT ao tentarem, por exemplo, criminalizar a homofobia. É preciso deixar claro que não se está a favor dos processos de violência aos quais a população LGBT está vulnerável em decorrência de suas orientações sexuais e identidades de gênero. Não se pretende negar ou invisibilizar tampouco as violências a que estão sujeitas todas as pessoas no quadro social contemporâneo, e onde esse contingente é especialmente alvo. Mas é preciso problematizar o que se faz com esses fenômenos e se a intenção, cada vez maior, de criminalizar práticas sociais é a solução encontrada para a erradicação de tais violências.

É fato cada vez mais contundente que a prisão, como instrumento de ressocialização e de responsabilização de um ato considerado criminoso é, em quase todos os casos (se não em todos), um engano. Se alguém contar sobre o período em que esteve preso e em como aprendeu sobre os valores de vida, de humanidade, de fraternidade, de cidadania e de empoderamento, poder-se-ia até considerar a prisão como uma estratégia válida. O raro, o quase impossível, no entanto, é ter conhecimento de um relato como esse, pois a regra é ouvir falar sobre como a prisão foi uma passagem sombria, densa, violenta, enlouquecedora, torturante. Mas, ao mesmo tempo, o que se ouve falar nos discursos do senso comum não diz respeito a essas vidas aprisionadas, afinal de contas o que está na prisão não faz parte do restante da sociedade: é lixo humano. É como aquilo que não presta e que se coloca dentro de uma sacola, e que, na maioria das vezes, não se fica sabendo o destino.

Se for levado em consideração ainda o que alguns teóricos têm chamado de seletividade penal (ZAFFARONI, 1999) - ou seja, o processo pelo qual a prisão captura essas vidas e no qual figuram especialmente as categorias de classe social, gênero e etnia/raça -, é impossível considerar natural e ingênuo o ingresso das pessoas na instituição prisional que deixou de ser (se é que já foi) uma instituição total. Seria como desconsiderar o pensamento de Foucault (1988) acerca do controle sobre os corpos, ou o que Zaffaroni (1999) fala com relação à incompetência do cárcere como política penal em vez de dispositivo de punição. Essas contradições são inerentes, portanto, às ações que primam pela criminalização de determinadas identidades, mesmo que nesse caso a identidade seja a heterossexual. Embora a categoria heterossexual não sofra a mesma discriminação que os LGBT, é alvo, nesses aspectos, de discursos aliados à ideia de criminalidade, quando na realidade a própria homofobia faz parte da ignorância de uma determinada ordem cultural e educacional.

Outra contradição aparente do movimento LGBT para acessar com mais facilidade as políticas públicas é o que acontece no processo transexualizador, em relação ao Sistema Único de Saúde ${ }^{8}$ (SUS). Atualmente no Brasil, as pessoas transexuais podem conquistar a redesignação sexual - ou cirurgia de transgenitalização através da rede pública de saúde, desde que passem pelo acompanhamento de uma equipe interdisciplinar que, passados dois anos, diagnosticará a disforia de gênero. Esse processo está amparado no pressuposto de que a transexualidade é uma doença, e que manter o corpo e a psique em desarmonia resultaria em transtorno da identidade de gênero, como defende o Código Internacional de Doenças (CID). Embora algumas correntes do movimento transexual no Brasil defendam a despatologização da transexualidade, a maioria dos grupos entende que manter a identidade transexual como doença tem servido de ferramenta para o acesso a esse direito.

\section{Considerações finais}

A criação e o fomento de políticas públicas, cabe afirmar, apresentam-se como bandeira principal dos movimentos sociais de gênero e sexualidade. Com a promulgação da Constituição da República em 1988, inicia-se o reconhecimento das desigualdades sociais objetivando a distribuição igualitária dos direitos sociais (COUTO, 2004). As políticas e as ações afirmativas de valorização da raça negra e da cultura indígena, os direitos e as chances iguais entre homens e mulheres se conformarão como as primeiras políticas públicas a serem pensadas no Brasil. A diversidade sexual, nesse cenário, será o último item a entrar na agenda antidiscriminatória federal, como bem mostram as datas de fundação da Frente Parlamentar Mista Pela Livre Expressão Sexual na Câmara dos Deputados (2003) e o Programa Brasil Sem Homofobia (2004), primeiras ações do governo nacional para essa população.

Os aspectos geradores de perversidade no trato da visibilidade política dos movimentos sociais de gênero e sexualidade ${ }^{9}$ dizem respeito ao papel das identidades que alguns movimentos assumem, acolhendo ou não determinados sujeitos na medida em que esses, em níveis diferentes se enquadram nas identidades particularizadas. Kich (2008, p. 129) abordará a ideia "de não heterossexualidades para definição das múltiplas formas de expressão de 'identidade' afetivo-sexual, compreendida como algo não fixo”, de modo que a identificação transcende até mesmo a orientação sexual e o gênero assumidos dos sujeitos para se tornar uma negociação entre a ordem do público e do privado tendo, portanto, ressonâncias políticas que podem ou não ser usadas como estratégias. A crítica à ideia das identidades está também no fato de que 
[...] alguns setores do movimento [colocam] suas identidades GLBTs como se fosse algo fixo, essencial. Dentro das discussões relacionadas ao tema no movimento GLBT brasileiro, a maior parte dos grupos reivindicatórios é bastante receptiva a ideias pós-identitárias, ou seja, os sujeitos não 'são' apenas uma identidade, e sim, uma infinidade de possibilidades identitárias. De modo bastante resumido, pode-se dizer que a crítica que se faz é a seguinte: se as identidades são múltiplas, não se 'é' apenas uma característica, como reivindicar políticas específicas para grupos determinados se a identidade fixa (no nosso exemplo GLBT) não existe? (TAQUES, 2007, p. 146).

Não se pode esquecer, contudo, que a assunção de uma identidade também tem um papel forte e positivo em uma sociedade que ainda clama pelo "não dito", ideia esta amparada por Green (2000, p. 291) ao dizer que "cada vez mais ativistas aparecem nos jornais, nas revistas e na televisão, tentando romper o código cultural que diz 'pode fazer o que você quiser, mas não diga nada a ninguém'”. Assumir-se gay foi, durante muito tempo, necessário em um determinado contexto histórico, e ainda o é em certas situações, porque justamente marca esse lugar do insubmisso, do que não sustenta a reprodução do status quo (muito embora alguns sustentem esse status já que ninguém está isento de reafirmar a heteronormatividade por meio de papéis heterossexualizantes, nem mesmo os LGBTs). Da mesma forma, outros ativistas adotam na contemporaneidade a cultura do respeito às sexualidades independente de quais sejam as identidades, sendo importante que essas duas doutrinas convivam - a da preservação da identidade e a da subversão delas - pois mantêm as contradições e os pluralismos do debate.

\section{Referências}

ALTHUSSER, L. Ideologia e aparelhos ideológicos do Estado. Lisboa: Editorial Presença, 1970.

BENTO, B. A reinvenção do corpo: sexualidade e gênero na experiência transexual. Rio de Janeiro: Garamond, 2006. (Coleção Sexualidade, Gênero e Sociedade).

BUTLER, J. Problemas de gênero: feminismo e subversão da identidade. Tradução de Renato Aguiar. Rio de Janeiro: Civilização Brasileira, 2010.

COLLING, L. O que a política trans do Equador tem a nos ensinar? In: SEMINÁRIO INTERNACIONAL FAZENDO GÊNERO: diásporas, diversidades, deslocamentos, 9., 2010. Florianópolis. Anais eletrônicos... Florianópolis: UFSC, 2010, p. 1-10.

COSTA, F. A.; MACHADO, F. V.; PRADO, M. A. M. Participação política e experiência homossexual: dilemas entre o indivíduo e o coletivo. Interamerican Journal of Psychology, Austin, v. 42, n. 2, p. 325-337, 2008.

COUTO, B. R. O direito social e a assistência social na sociedade brasileira: uma equação possível? São Paulo: Cortez, 2004.

FERNANDES, I. O lugar da identidade e das diferenças nas relações sociais. Textos \& Contextos, Porto Alegre, v. 5, n. 2, p. 1-12, dez. 2006. FOUCAULT, M. História da sexualidade I: a vontade de saber. Tradução de Maria Thereza da Costa Albuquerque e J. A. Guilhon Albuquerque. Rio de Janeiro: Graal, 1988.

FROEMMING, C. N. Equidade, universalidade e materialização dos direitos - possibilidades de atuação do Serviço Social. In: POCAHY, F. A. (Org.). Rompendo o silêncio: homofobia e heterossexismo na sociedade contemporânea. Políticas, teoria e atuação. Porto Alegre: nuances, 2007.

GREEN, J. N. "Mais amor e mais tesão": a construção de um movimento brasileiro de gays, lésbicas e travestis. Cadernos Pagu, Campinas, n. 15, p. 271-295, jan./jun. 2000.

GODINHO, T. Apresentação. Cadernos Democracia Socialista, São Paulo, v. 8, p. 1-2, 1989.

GOHN, M. da G. Os sem-terra, ONGs e cidadania: a sociedade civil brasileira na era da globalização. São Paulo: Cortez, 1997.

ILGA-Internacional Lesbian, Gay, Bissexual, Trans and Intersex Association. Direitos de lésbicas e gays no mundo. Bruxelas. Disponível em: <http://ilga.org/ilga/pt/index.html>. Acesso em: 20 jan. 2013.

. Homofobia de Estado: un informe mundial sobre las leyes que criminalizan la actividad sexual con consentimento entre personas adultas del mismo sexo. Bruxelas. Disponível em: <http://ilga.org/ilga/pt/index.html〉. Acesso em: 20 jan. 2013.

JESUS, J. G. de. O protesto na festa: política e carnavalização nas paradas do orgulho de LGBT. 2010. 194 f. Tese (Doutorado em Psicologia Social, do Trabalho e das Organizações) - Instituto de Psicologia, UnB, Brasília, 2010.

KICH, F. D. Da invisibilidade à visibilidade política: homossexualidade e processos de ruptura no Brasil. Revista Fórum Identidades, Sergipe, ano 2, v. 3, p. 129-136, jan./jun. 2008.

LAFARGUE, P. Porque crê em Deus a burguesia. Tradução de Jaime Ferreira Dias. Portugal: Republica Social, 1932.

LOURO, G. L. Gênero, sexualidade e educação: uma perspectiva pós-estruturalista. Rio de Janeiro: Vozes, 1997.

. Teoria Queer - uma política pós-identitária para a educação. Estudos Feministas, Florianópolis, v. 9, n. 2, p. 541-553, 2001.

MAGISTÉRIO DA IGREJA. Catecismo da Igreja Católica (em português). Coimbra: Gráfica de Coimbra, 2000.

MISKOLCI, R. Pânicos morais e controle social - reflexões sobre o casamento gay. Cadernos Pagu, Campinas, n. 28, p. 101-128, jan./jun. 2007. 
. A Teoria Queer e a questão das diferenças: por uma analítica da normalização. In: CONGRESSO DE LEITURA DO BRASIL (COLE), 16., 2007. Campinas: Associação de Leitura do Brasil. Disponível em: <http://xa.yimg.com/kq/groups/24805135/427522231/ name/prog03_01.pdf>. Acesso em: 7 fev. 2013.

2009.

.A Teoria Queer e a Sociologia: o desafio de uma analítica da normalização. Sociologias, Porto Alegre, n. 21, p. 150-182, jan./jun.

MOTT, L. R. Homossexualidade: mitos e verdades. Salvador: Ed. GGB, 2003.

NOBRE, M.; WERLE, D. L. Dossiê tolerância - apresentação. Novos estudos Cebrap, São Paulo, n. 84, p. 5-12, 2009.

SCOTT, J. W. Gênero: uma categoria útil de análise histórica. Educação \& Realidade, Porto Alegre, v. 20, n. 2, p. 71-99, jul./dez. 1995.

SILVEIRA, M. L. S. da. Algumas notas sobre a temática da subjetividade no âmbito do marxismo. Revista Outubro Vermelho, Campinas, n. 7, 2002.

SOUZA, M. L. Desenvolvimento de comunidade e participação. São Paulo: Cortez, 1991.

TAQUES, F. J. Movimento GLBT: considerações necessárias. Ciências Sociais Unisinos, v. 43, n. 2, p. 144-148, maio/ago. 2007. TREVISAN, J. S. Devassos no paraíso: a homossexualidade no Brasil, da colônia à atualidade. Rio de Janeiro: Record, 2004.

ULLMANN, R. A. Amor e sexo na Grécia Antiga. Porto Alegre: Edipucrs, 2007. (Coleção Filosofia, 194).

WAGNER, L. Serviço Social e movimentos sociais - uma não-relação? Civitas, Porto Alegre, v. 4, n. 1, p. 133-141, jan./jun. 2004.

ZAFFARONI, E. R. Em busca das penas perdidas: a perda de legitimidade do sistema penal. Rio de Janeiro: Revan, 1999.

\section{Notas}

1 Lésbicas, gays, bissexuais, travestis e transexuais.

2 Tais instituições ideológicas guardam correspondência ao que Althusser (1970) define como Aparelhos Ideológicos de Estado (AIE). São aquelas instituições especializadas responsáveis por reproduzirem a ideologia de acordo com as suas naturezas: os sistemas religiosos, escolares, familiares, jurídicos, políticos, sindicais, culturais e de informação são os aparelhos citados pelo autor, que se diferenciam do aparelho repressivo do Estado por funcionarem prevalentemente pela ideologia e secundariamente pela violência (pois mobilizam violências de forma dissimulada ou simbólica).

3 Os países que punem as relações homossexuais com o aprisionamento são: Belize, Jamaica, Antíguae Barbuda, São Cristóvão e Nevis, São Vicente e Granadinas, Dominica, Santa Lúcia, Grenada, Barbados, Trinidad e Tobago, e Guiana (ILGA, 2012).

4 "Por heteronormatividade entendemos aquelas instituições, estruturas de compreensão e orientações práticas que não apenas fazem com que a heterossexualidade pareça coerente- ou seja, organizada como sexualidade -mas também que seja privilegiada. Sua coerênciaé sempre provisional e seu privilégio pode adotar várias formas (que às vezes são contraditórias): passa despercebida como linguagem básica sobre os aspectos sociais e pessoais; é percebida como um estado natural; também se projeta como um objetivo ideal ou moral" (BERLANT; WARNER, 2002 apud MISKOLCI, 2007, p. 5).

5 O ano 1968 é marcado pela história como um marco da rebeldia e da contestação (LOURO, 1997), onde diferentes grupos e organizações de pessoas rejeitam as formas como certos arranjos políticos e sociais se estabelecem, dentre eles, os tocantes às diferenças entre mulheres e homens.

6 Um bom exemplo disso pode ser conferido no uso contemporâneo do termo "homoafetivo", cunhado pela primeira vez pela desembargadora aposentada do Tribunal de Justiça do Rio Grande do Sul, Maria Berenice Dias, em sua obra União homossexual: o preconceito \& a justiça, no intuito de definir uniões entre pessoas do mesmo sexo como baseadas também no afeto, pretendendo desestimular a ideia de que as relações entre homossexuais se dão apenas na perspectiva do prazer sexual. Embora seja, para alguns, uma conquista, pois reconheceria que a parceria entre casais de homossexuais também constitui unidade familiar, é, ao mesmo tempo, instrumento de normalização e normatização, pois coloca o homossexual - anteriormente desviado e amoral - como indivíduo possível de se incluir a costumes burgueses e capitalistas bem proclamados por todos, como a monogamia e o "bom comportamento". É uma maneira, portanto, de reconhecer a identidade homossexual, incluindo-a na dinâmica heterossexual, sem, contudo, questionar essa dinâmica, pois mantêm determinados sujeitos na pretensa anormalidade.

7 Sem longas detenções sobre o conceito, é possível dizer que o termo queer com relação à sexualidade e ao gênero (que traduzido literalmente significa "estranho") surgiu como um insulto aos gays e lésbicas norte-americanos, os quais passaram a utilizar a palavra como forma de assunção e de deboche, contestando os padrões de normalidade e de estabilidade propostas pela heterossexualidade compulsória e potencializados pelas políticas de identidade do movimento homossexual dominante (LOURO, 2001).

8 Atualmente no Brasil, as pessoas transexuais podem acessar a troca de sexo apenas em quatro cidades: Porto Alegre, Goiás, São Paulo e Rio de Janeiro.

9 Tais aspectos de perversidade estão relacionados à utilização de políticas e editais de financiamento que reforçam vulnerabilidades (no caso dos gays, os projetos de HIV/aids) e também à criminalização de outras identidades (novamente no caso dos LGBT, da identidade heterossexual, cujas práticas são homofóbicas) para reafirmação de suas próprias pertenças à dinâmica social. 


\section{Guilherme Gomes Ferreira}

guih@live.it

Mestrando do Programa de Pós-Graduação em Serviço Social da Pontifícia Universidade Católica do Rio Grande do Sul (PUCRS)

\section{Beatriz Gershenson Aguinsky}

aguinsky@pucrs.br

Doutora em Serviço Social pela PUCRS

Professora titular da Faculdade de Serviço Social da PUCRS

\section{PUCRS - Faculdade de Serviço Social}

Av. Ipiranga, 6681

Partenon

Porto Alegre - Rio Grande do Sul - Brasil

CEP: 90619900 